\title{
Arctic stratospheric dehydration - Part 1: Unprecedented observation of vertical redistribution of water
}

\author{
S. M. Khaykin ${ }^{1,2}$, I. Engel ${ }^{3,6}$, H. Vömel ${ }^{4}$, I. M. Formanyuk ${ }^{1}$, R. Kivi ${ }^{5}$, L. I. Korshunov ${ }^{1}$, M. Krämer ${ }^{6}$, A. D. Lykov ${ }^{1}$, \\ S. Meier ${ }^{4}$, T. Naebert ${ }^{4}$, M. C. Pitts ${ }^{7}$, M. L. Santee ${ }^{8}$, N. Spelten ${ }^{6}$, F. G. Wienhold ${ }^{3}$, V. A. Yushkov ${ }^{1}$, and T. Peter ${ }^{3}$ \\ ${ }^{1}$ Central Aerological Observatory of Roshydromet, Dolgoprudny, Moscow Region, Russia \\ ${ }^{2}$ LATMOS, CNRS-INSU, UMR8190, Université de Versailles St. Quentin, Guyancourt, France \\ ${ }^{3}$ ETH Zurich, Institute for Atmospheric and Climate Science, Zurich, Switzerland \\ ${ }^{4}$ DWD Meteorologisches Observatorium Lindenberg, Lindenberg, Germany \\ ${ }^{5}$ Finnish Meteorological Institute, Arctic Research Centre, Sodankylä, Finland \\ ${ }^{6}$ Forschungszentrum Jülich, Institute for Energy and Climate Research (IEK-7), Jülich, Germany \\ ${ }^{7}$ NASA Langley Research Center, Hampton, Virginia, USA \\ ${ }^{8}$ JPL/NASA, California Institute of Technology, Pasadena, California, USA
}

Correspondence to: S. M. Khaykin (sehamic@yandex.ru)

Received: 10 May 2013 - Published in Atmos. Chem. Phys. Discuss.: 30 May 2013

Revised: 23 October 2013 - Accepted: 24 October 2013 - Published: 27 November 2013

\begin{abstract}
We present high-resolution measurements of water vapour, aerosols and clouds in the Arctic stratosphere in January and February 2010 carried out by in situ instrumentation on balloon sondes and high-altitude aircraft combined with satellite observations. The measurements provide unparalleled evidence of dehydration and rehydration due to gravitational settling of ice particles. An extreme cooling of the Arctic stratospheric vortex during the second half of January 2010 resulted in a rare synoptic-scale outbreak of ice polar stratospheric clouds (PSCs) remotely detected by the lidar aboard the CALIPSO (Cloud-Aerosol Lidar and Infrared Pathfinder Satellite Observation) satellite. The widespread occurrence of ice clouds was followed by sedimentation and consequent sublimation of ice particles, leading to vertical redistribution of water inside the vortex. A sequence of balloon and aircraft soundings with chilled mirror and Lyman- $\alpha$ hygrometers (Cryogenic Frostpoint Hygrometer, CFH; Fast In Situ Stratospheric Hygrometer, FISH; Fluorescent Airborne Stratospheric Hygrometer, FLASH) and backscatter sondes (Compact Optical Backscatter Aerosol Detector, COBALD) conducted in January 2010 within the LAPBIAT (Lapland Atmosphere-Biosphere Facility) and RECONCILE (Reconciliation of Essential Process Parameters for an Enhanced Predictability of Arctic Stratospheric Ozone Loss and its Climate Interactions) campaigns
\end{abstract}

captured various phases of this phenomenon: ice formation, irreversible dehydration and rehydration. Consistent observations of water vapour by these independent measurement techniques show clear signatures of irreversible dehydration of the vortex air by up to $1.6 \mathrm{ppmv}$ in the $20-24 \mathrm{~km}$ altitude range and rehydration by up to $0.9 \mathrm{ppmv}$ in a $1 \mathrm{~km}$ thick layer below. Comparison with space-borne Aura MLS (Microwave Limb Sounder) water vapour observations allow the spatiotemporal evolution of dehydrated air masses within the Arctic vortex to be derived and upscaled.

\section{Introduction}

Water vapour in the polar stratosphere plays a significant role in ozone chemistry and is an important indicator of polar vortex dynamics. Water vapour within the stratospheric vortex is generally characterized by a gradual increase of mixing ratio with height, due to subsidence of air masses from higher altitudes (where water is produced by methane oxidation). Conversely, in the cold and stable Antarctic vortex, the water mixing ratio can be reduced to 1.5 ppmv (Vömel et al., 1995) as the water freezes into ice particles, sedimenting and sublimating at lower altitudes, and thus causing an irreversible dehydration, i.e. removal of water from a certain air mass. 
The same may apply to the other components in the particle phase, such as $\mathrm{HNO}_{3}$, which results in denitrification, an effect that prolongs the time of ozone destruction via chlorineinduced catalytic cycles (Salawitch et al., 1993). Hence the gravitational settling of solid polar stratospheric cloud (PSC) particles may cause a dramatic change in the chemical composition of the polar vortex, and subsequently also of the mid-latitude stratosphere (due to release of chemically perturbed air from the vortex after its breakup).

Due to the persistent low temperature, formation of ice PSC and dehydration are large-scale climatological features in the Antarctic winter (e.g. Nedoluha et al., 2000; Stone et al., 2001). In contrast, the occurrence of ice clouds in the Arctic vortex is much less frequent or severe. In fact, local reductions of water vapour mixing ratios associated with ice formation have only been documented for sporadic events during the coldest winters in the Arctic stratosphere, namely 1988/89 (Fahey et al., 1990), 1994/95 (Ovarlez and Ovarlez, 1994), 1995/96 (Vömel et al., 1997; Hintsa et al., 1998), 1996/97 (Pan et al., 2002), 1999/2000 (Schiller et al., 2002) and 2004/05 (Jimenez et al., 2006; Maturilli and Dörnbrack, 2006). The most severe episode of water depletion in the presence of ice PSCs in the Arctic has been reported by Vömel et al. (1997), whose balloon-borne water vapour measurements revealed a reduction in mixing ratio of 2 ppmv. Except the pioneering work of Fahey et al. (1990) and Vömel et al. (1997), all other above-mentioned authors link the observed dehydration episodes in the Arctic to mesoscale cooling events induced by orographic perturbations above mountains. Indeed, the majority of Arctic ice PSC observations are documented for Scandinavia (e.g. Kivi et al., 2001), where gravity waves with amplitudes large enough to reduce the temperature by several degrees below the ice frost point ( $\left.T_{\text {frost }}\right)$ are frequently excited (e.g. Dörnbrack et al., 1999). The wave-induced ice clouds are characterized by high number densities $\left(n_{\text {ice }}>1 \mathrm{~cm}^{-3}\right)$ of small $\left(r_{\text {ice }} \sim 1-1.5 \mu \mathrm{m}\right)$ ice particles with a short lifetime and very slow sedimentation rate (e.g. Fueglistaler et al., 2003). Although it has been hypothesized that the sublimation of ice particles formed after a rapid cooling might be deferred by a coating of nitric acid tryhydrate (NAT) (Peter et al., 1994), laboratory work has lent only little support to this hypothesis (Biermann et al., 1998), so the dehydration potential of the short exposure of the air to highly localized mountain-wave ice clouds might be small. Indeed, the signatures of irreversible dehydration and rehydration as a consequence of growth and evaporation of sedimenting particles have not been documented for the Arctic so far.

Due to lack of in situ observations in the presence of PSCs, some uncertainties regarding the boundary conditions and the pathways of ice clouds formation still remain. While homogeneous freezing of supercooled ternary solution (STS) particles has been the generally accepted formation pathway of ice PSCs, new results - mainly triggered by space-borne observations using the CALIPSO (Cloud-Aerosol Lidar and
Infrared Pathfinder Satellite Observation) satellite - suggest that heterogeneous nucleation plays a major role (Pitts et al., 2011; Engel et al., 2013a). Homogeneous nucleation of ice requires temperatures $3-4 \mathrm{~K}$ below the frost point, $T_{\text {frost }}$ (Koop et al., 1995). Heterogeneous formation pathways of ice have been discussed in the past; for example, the original three-stage model proposed by Drdla and Turco (1991), suggested homogenous nucleation of solid sulphuric acid hydrates in the stratospheric aerosol droplets, which then serve as heterogeneous nuclei for NAT particles, which in turn serve as heterogeneous nuclei for ice. Still, there is little support from field or laboratory studies favouring the formation of sulphuric acid hydrates. However, the idea of ice particles nucleating heterogeneously on pre-existing NAT particles was brought up again by Pitts et al. (2011), who observed the increase in synoptic-scale ice PSCs concomitant with a decrease of NAT mixture clouds in January 2010. This process would imply that sedimenting ice particles not only dehydrate, but also denitrify the stratosphere due to the enclosed $\mathrm{HNO}_{3}$, a possibility discussed in most of the above-mentioned work. Khosrawi et al. (2011) also offered this as a possible explanation for the low $\mathrm{HNO}_{3}$ recorded by ODIN/SMR during the 2009/10 Arctic winter. Non-volatile particles, observed in up to $80 \%$ of the detected sub-micron particles in the Arctic vortex (von Hobe et al., 2013), could be another source of heterogeneous nuclei of NAT and ice, facilitating their formation. Their origin is still unclear and might be, for example, meteoritic or anthropogenic. Recent studies by Hoyle et al. (2013) and Engel et al. (2013a) highlight the importance of this pathway for NAT and ice nucleation. Obviously, the verification and correct parameterization of the heterogeneous ice formation requires accurate in situ measurements in the presence of ice PSCs, which have been not available until now.

The high-quality in situ observations presented here, including those acquired during the very process of ice PSC formation, provide a reference for representation of ice cloud formation in microphysical models. A microphysical modelling study making use of these observations is presented in the companion paper (Engel et al., 2013b) and relates the question of ice formation pathways and concurrent dehydration to the observations described here.

The Arctic winter 2009/2010 was characterized by extremely low temperatures encountered in the vortex during the second half of January 2010. These conditions, unusual for the Arctic stratosphere, led to a major outbreak of ice PSCs detected by the CALIPSO space-borne lidar (Pitts et al., 2011). Extreme temperatures and ice clouds persisted on a synoptic scale from 15 through 21 January, causing - as concluded in this study - significant vertical redistribution of water within the stratospheric vortex. The extensive aircraft and balloon measurements conducted across Northern Scandinavia from January to March 2010 were accompanied by space-borne observations, opening the way for a detailed investigation of this rare phenomenon. The evolution 
of dehydration and rehydration, and its amplitude and vertical extent, are inferred from a sequence of balloon and satellite water vapour observations. The source region of dehydration and its spatial development are identified using satellite water vapour maps.

The paper is organized as follows: Sect. 2 gives a detailed description of experimental set-up and instrumentation used. Section 3 discusses the meteorological conditions in the stratosphere during January 2010, presents the observational results, and identifies the source region and spatiotemporal evolution of dehydration. Section 4 concludes the paper. A comprehensive trajectory-based microphysical modelling study, connecting the individual balloon-borne observations, is provided in the companion paper by Engel et al. (2013b).

\section{Experimental setup and instrumentation}

During the winter 2009/10 a number of extensive measurement activities were carried out in the Arctic stratosphere. Our study makes use of a series of balloon, aircraft, and satellite observations of water vapour and aerosol backscatter obtained using various measurement platforms and techniques. The water vapour measurements were provided by the balloon-borne CFH (Cryogenic Frostpoint Hygrometer) and FLASH-B (Fluorescence Lyman- $\alpha$ Stratospheric Hygrometer for Balloons) sondes, the aircraft-borne FISH (Fast In Situ Stratospheric Hygrometer) and FLASH-A (Fluorescent Lyman- $\alpha$ Stratospheric Hygrometer for Aircraft) or "FLASH-A" and "FLASH-B" hygrometers and the spaceborne Aura MLS (Microwave Limb Sounder) instrument, while backscatter measurements were provided by balloonborne COBALD (Compact Optical Backscatter Aerosol Detector) aerosol sondes and the CALIPSO lidar. The balloon and aircraft measurements are courtesy of LAPBIAT-II (Lapland Atmosphere-Biosphere Facility) and RECONCILE (Reconciliation of Essential Process Parameters for an Enhanced Predictability of Arctic Stratospheric Ozone Loss and its Climate Interactions) field campaigns, respectively, both of which were carried out in the Arctic from January-March 2010.

\subsection{Balloon soundings}

The balloon-borne measurements of water vapour, temperature and particles were obtained within the LAPBIAT-II atmospheric sounding campaign carried out in Sodankylä, Finland $\left(67.4^{\circ} \mathrm{N}, 26.6^{\circ} \mathrm{E}\right)$ under the auspices of the Finnish Meteorological Institute Arctic Research Centre (FMI-ARC). The majority of the balloon flights was conducted in close timing with deployments of the stratospheric research aircraft M55-Geophysica, operating from Kiruna, Sweden, $360 \mathrm{~km}$ west of Sodankylä. The balloon soundings were implemented in two phases, with 18 launches during 17
January-6 February 2010 (see Table 1) and 15 launches during 10-24 March 2010. Altogether 172 individual balloon instruments were flown during the campaign (Kivi et al., 2010). The analysis of this study is restricted to the data obtained within the first deployment phase, corresponding to the period of coldest stratospheric temperatures.

Table 1 provides an overview of the balloon-borne measurements of stratospheric water vapour and backscatter conducted during LAPBIAT-II. Two types of hygrometers were used: CFH and FLASH-B. For aerosol and cloud measurements, the balloons were equipped with a COBALD backscatter sonde. During the first phase of LAPBIAT-II, the CFH instrument was part of 15 payloads, 11 of which also included the COBALD backscatter sonde, 4 of which included FLASH-B sondes and 2 of which included, in addition to COBALD, the backscatter sonde of the University of Wyoming (Rosen and Kjome, 1991), denoted by "BKS" in Table 1. All payloads were suspended $50 \mathrm{~m}$ below the balloon using an unwinder device in order to minimize the balloon outgassing effect. Temperature and pressure in all flights were measured using the Vaisala RS-92 radiosonde. The altitude used in this study is that of the GPS and the potential temperature is that calculated from pressure and temperature provided by the Vaisala RS-92 radiosonde.

\subsubsection{Cryogenic Frostpoint Hygrometer (CFH)}

CFH has been developed at the University of Colorado (Vömel et al., 2007a). It is a small lightweight balloonborne hygrometer, based on the chilled mirror technique. Like many chilled mirror instruments, $\mathrm{CFH}$ is not calibrated for water vapour, but is considered an absolute reference for water vapour measurements. It measures the temperature at which an ice layer is in equilibrium with the gas phase of water passing over this ice layer. The largest source of uncertainty in CFH water vapour measurements is the stability of the feedback controller, which maintains the constant frost layer on the mirror. In most cases the feedback controller will lead to slight oscillations around the true frost point, which may have an amplitude of somewhere between $0.1^{\circ} \mathrm{C}$ (for well stabled instruments) and $1.0^{\circ} \mathrm{C}$ (for slightly unstable instruments). The total uncertainty in frost point is better than $0.5 \mathrm{~K}$ throughout the entire profile (Vömel et al., 2007a), which translates to a mixing ratio uncertainty of about $10 \%$ in the lower and middle stratosphere. The only limitations are measurements inside liquid clouds, which may disable the instrument due to wetting of the detector lens, and contamination at altitudes above $26-27 \mathrm{~km}$ during the ascent leg due to outgassing from the balloon or any other surface of the flight train. The data processing includes a step with the aim of screening out these artefacts and, if necessary, applying running average over $40 \mathrm{~s}$ interval. The quality of descent measurements by CFH can deteriorate because of the controller's inability to properly respond to the changes in water vapour 
Table 1. Listing of water vapour and aerosol soundings conducted during the first phase of the LAPBIAT-II campaign, January/February 2010, Sodankylä, Finland. The soundings which did not provide useful data in the stratosphere due to technical issues are not listed. From left to right: date and time of the balloon launch; hygrometer type used (FLB=FLASH-B); backscatter sonde used (BKS = Wyoming backscatter sonde); indicator of ice occurrence (I), STS or NAT/liquid mixture clouds (M), dehydration (D) or rehydration (R) signatures (identified as deviation of the vertical profiles from the $10 \mathrm{yr}$ January mean profile); maximum amplitude of dehydration or rehydration signal, negative or positive, respectively (in ppmv). All soundings included ECC ozone sondes.

\begin{tabular}{lrrrrr}
\hline Date & $\begin{array}{r}\text { Time } \\
\text { (UTC) }\end{array}$ & $\begin{array}{r}\text { Hygrometer } \\
\text { sonde }\end{array}$ & Backscatter & Indicator & $\begin{array}{r}\text { Amplitude } \\
(\mathrm{ppmv})\end{array}$ \\
\hline 17.01 .2010 & $19: 47$ & CFH, FLB & COBALD & I, D & -1.3 \\
20.01 .2010 & $15: 25$ & CFH & COBALD & M & \\
21.01 .2010 & $09: 26$ & CFH & & D, R & $-0.7 /+0.6$ \\
22.01 .2010 & $04: 18$ & CFH & COBALD & D, M & -0.6 \\
22.01 .2010 & $19: 08$ & CFH & COBALD, BKS & D, M & -1.0 \\
23.01 .2010 & $17: 30$ & CFH & COBALD, BKS & D, R, M & $-1.6 /+0.9$ \\
25.01 .2010 & $00: 00$ & CFH, FLB & COBALD & D, R & $-0.8 /+0.6$ \\
25.01 .2010 & $18: 13$ & CFH & COBALD & D, M & -0.8 \\
28.01 .2010 & $16: 44$ & CFH, FLB & COBALD & D, R & $-0.7 /+0.5$ \\
29.01 .2010 & $17: 12$ & CFH, FLB & COBALD & D & -0.8 \\
02.02 .2010 & $12: 27$ & CFH & & & \\
03.02 .2010 & $20: 11$ & CFH & COBALD & D, R & $-0.5 /+0.4$ \\
06.02 .2010 & $17: 15$ & CFH & COBALD & D & -0.3 \\
\hline
\end{tabular}

at high vertical speed reaching $60 \mathrm{~m} \mathrm{~s}^{-1}$ in the stratosphere. Therefore only ascent measurements are used in this study.

\subsubsection{Fluorescence Lyman- $\alpha$ Stratospheric Hygrometer (FLASH-B)}

The balloon version of FLASH is a compact lightweight sonde developed at the Central Aerological Observatory, Russia, for balloon-borne water vapour measurements in the upper troposphere and stratosphere (Yushkov et al., 1998). The instrument is based on the fluorescent method (Kley and Stone, 1978; Bertaux and Delannoy, 1978), which uses the photodissociation of $\mathrm{H}_{2} \mathrm{O}$ molecules exposed to vacuum ultraviolet radiation $(\lambda<137 \mathrm{~nm})$ followed by the measurement of the fluorescence of excited $\mathrm{OH}$ radicals using a Hamamatsu photomultiplier. The intensity of the fluorescent light sensed by the photomultiplier is directly proportional to the water vapour mixing ratio under stratospheric conditions $(10-150 \mathrm{hPa})$. The $\mathrm{H}_{2} \mathrm{O}$ measurement range is limited to pressures lower than $300-400 \mathrm{hPa}$ due to strong Lyman- $\alpha$ absorption in the lower troposphere. The instrument uses an open optical layout design, where the analysed volume is located outside the instrument, which allows a reduction in the size of the instrument to a small sonde with a total weight of about $1 \mathrm{~kg}$ including batteries. This arrangement restricts the use of the instrument to night-time only.

Each FLASH-B instrument is calibrated in the laboratory against a reference dew point hygrometer, MBW $373 \mathrm{~L}$. A description of the procedure can be found in Vömel et al. (2007b). The detection limit for a $4 \mathrm{~s}$ integration time at stratospheric conditions is of the order of $0.1 \mathrm{ppmv}$, while the accuracy is limited by the calibration error, which amounts to $4 \%$. The typical precision in the stratosphere is $5-6 \%$, whereas the total uncertainty is less than $10 \%$. While the minimum response time of the FLASH-B is $0.2 \mathrm{~s}$, here we use the data averaged over $4 \mathrm{~s}$, resulting in a vertical resolution of $20 \mathrm{~m}$ during ascent and $100 \mathrm{~m}$ during the fast descent ( $15 \mathrm{~m} \mathrm{~s}^{-1}$ around the tropopause) in the stratosphere. The flight configuration of FLASH-B, in which the analysed volume is located beneath the downward-looking optics $2-3 \mathrm{~cm}$ away from the lens, caused noticeable self-contamination due to water outgassing from the instrument and possibly also from other equipment and the balloon above about $70 \mathrm{hPa}$ during the ascent. By contrast, the FLASH-B measurements during the fast descent at the bottom of the flight train in undisturbed air are contamination-free as shown by the drop of water vapour readings immediately after the burst of balloon. Accordingly, only descent data are used in this study.

Intercomparison of the stratospheric water vapour measurements by FLASH-B and by CFH used in this study (Table 1) show a mean difference between the profiles above $14 \mathrm{~km}$ of $0.78 \%$ (with $1 \sigma$ standard deviation of $4 \%$ and good consistency in reproducing vertical structures. Additional information on the intercomparison is provided in supplementary material. Excellent agreement between the water vapour profiles obtained using two different techniques suggests high quality of the measurements and allows for using FLASH-B and CFH measurements as coherent data series. 


\subsubsection{Compact Optical Backscatter Aerosol Detector (COBALD)}

COBALD was developed at ETH Zurich as a successor to the Wyoming backscatter sonde of Rosen and Kjome (1991). With a total weight of approximately $550 \mathrm{~g}$ including batteries, the instrument can be flown on operational weather balloons and thus facilitates practical application. COBALD measures molecular, aerosol and cloud particle backscatter in the atmosphere from the ground to the level of balloon burst. Two LEDs with $250 \mathrm{~mW}$ optical power each emit light at wavelengths of 455 and $870 \mathrm{~nm}$. To register the backscattered light, a photodiode is placed between the LEDs, and the associated optics establishes an overlap region at distances larger than $0.5 \mathrm{~m}$ in front of the instrument. So far, the instrument is designed for applications during night-time only, as solar radiation saturates the detector.

Backscatter by molecules and aerosols contributes to the measured signal, whose separation is achieved following Rosen and Kjome (1991). The molecular number density is determined from temperature and pressure recorded simultaneously by the hosting radiosonde. Together with certain conservative assumptions about aerosol loading in regions of clean air, the normalization of the backscatter signal yields the backscatter ratio $(B S R)$ defined as the ratio of the total - aerosol and molecular - backscatter to molecular signal. Analogously to the $B S R$ the aerosol backscatter ratio is $A B S R=B S R-1$. The two different wavelengths allow definition of the colour index (CI) as the ratio of the $A B S R$ at $870 \mathrm{~nm}$ divided by the $A B S R$ at $455 \mathrm{~nm}$. Information on particle size can be obtained from the CI is subject to certain assumptions about particle size distribution, shape and refractive index. For the COBALD wavelengths, the range of CI varies from the Rayleigh limit of 1 (for very small particles) up to approximately 14 (for large particles in the geometric limit, with a radius of approximately around $2 \mu \mathrm{m}$ ). It should be noted that it is possible for the CI to significantly exceed 14 before reaching large particle values, because scattering functions oscillate about the asymptotic limit. These Mie oscillations cause ambiguity and thus inhibit distinct radius information for certain sizes. Stratospheric background aerosols are known to be characterized by a CI of 5 (Rosen and Kjome, 1991).

Usage of the Wyoming backscatter sonde has ranged from observations of volcanic aerosol (Rosen et al., 1992) over cirrus (e.g. Beyerle et al., 2001) to polar stratospheric clouds (e.g. Larsen et al., 2004). The new COBALD sonde has started to be applied in various field studies (e.g. Bukowiecki et al., 2011; Brabec et al., 2012). The COBALD BSR profiles used here are binned to $1 \mathrm{hPa}$ pressure intervals to reduce measurement noise, which typically increases in the stratosphere.

\subsection{M55-Geophysica aircraft measurements}

In the frame of the European research project RECONCILE, an intensive field campaign of coordinated aircraft, balloon and ground-based measurements related to ozone chemistry and PSCs, was conducted during January-March 2010 (von Hobe et al., 2012). The Russian high-altitude aircraft M55-Geophysica was deployed in Kiruna, Sweden and conducted 12 research flights carrying over 20 in situ and remote instruments for the measurement of gaseous and particle constituents. In accordance with the balloon soundings in Sodankylä, the aircraft campaign was implemented in two phases.

The in situ water vapour instruments operating onboard the M55-Geophysica aircraft are FISH and FLASH-A both closed-cell hygrometers that use the fluorescent method for measuring water vapour in the upper troposphere and lower stratosphere with $1 \mathrm{~Hz}$ sampling frequency. The Fast In-situ Stratospheric Hygrometer (FISH) is equipped with a forward-facing inlet and thus measures total water, i.e. the sum of gas-phase water and ice particles. The description and the calibration procedure of the FISH instrument have been documented by Zöger et al. (1999) and Schiller et al. (2008). Mixing ratios of $\mathrm{H}_{2} \mathrm{O}$ between 0.5 and 1000 ppmv can be detected by FISH with a time resolution of $1 \mathrm{~s}$ and an overall accuracy of $6 \%$. FISH was calibrated regularly before and after every flight during the aircraft campaign using a calibration bench that included a frost point hygrometer (MBW DP30) as a reference.

FLASH-A (Fluorescent Lyman- $\alpha$ Stratospheric Hygrometer for Aircraft) is a recent modification of the FLASH instrument (Sitnikov et al., 2007) previously utilized onboard the M55-Geophysica aircraft. FLASH-A has a rear-facing inlet for the measurement of gas-phase water vapour in the altitude range between 7 and $20 \mathrm{~km}$, with the upper limit being the aircraft ceiling altitude. Its total measurement uncertainty amounts to $10 \%$ for a $6 \mathrm{~s}$ integration time with a detection limit of 0.2 ppmv. During the RECONCILE campaign, FLASH-A was calibrated after every third flight using the FISH calibration bench. The signal-to-noise ratio of the FLASH-A instrument is lower than that of FISH for $1 \mathrm{~s}$ resolution data, therefore we use $6 \mathrm{~s}$ averaged data in this study. The point-by-point comparison between FLASH-A and FISH stratospheric cloud-free data acquired during the RECONCILE flights showed a mean relative difference of $2.7 \%$ (with $1 \sigma$ standard deviation of $3 \%$ ), which is well within the uncertainty limits of both hygrometers. The details of airborne hygrometers intercomparison are provided in supplementary material.

\subsection{Microwave Limb Sounder (MLS)}

The MLS instrument operating onboard Aura satellite was launched in July 2004 as a part of the NASA/ESA "A-Train" satellite constellation. MLS is a limb-sounding instrument 
that measures the thermal emission at millimetre and submillimetre wavelengths using seven radiometers to cover five broad spectral regions (Waters et al., 2006). Measurements are performed from the surface to $90 \mathrm{~km}$ with global latitude coverage from $82^{\circ} \mathrm{S}$ to $82^{\circ} \mathrm{N}$ each day. Here we use the version v3.3 described by Livesey et al. (2011), who reports for the middle stratosphere with a vertical resolution of 3.1$3.3 \mathrm{~km}$, a horizontal resolution of $220-300 \mathrm{~km}$, an accuracy of $7-9 \%$ and a precision of $6 \%$. The data screening criteria specified by Livesey et al. (2011) have been applied to the data.

\subsection{Cloud-Aerosol Lidar with Orthogonal Polarization (CALIOP)}

CALIPSO is a part of the "A-Train" satellite constellation and has been in operation since June 2006 (Winker et al., 2009). CALIPSO is in a $98.2^{\circ}$ inclination orbit which provides extensive measurements over the polar regions of both hemispheres up to $82^{\circ}$ in latitude. Measurements of PSCs are provided by CALIOP (Cloud-Aerosol Lidar with Orthogonal Polarization), the primary instrument onboard CALIPSO, which is a two-wavelength, polarization-sensitive lidar. High vertical resolution profiles of the backscatter coefficient at 532 and $1064 \mathrm{~nm}$ as well as two orthogonal (parallel and perpendicular) polarization components at $532 \mathrm{~nm}$ are provided (Pitts et al., 2007). The lidar pulse rate is $20.25 \mathrm{~Hz}$, corresponding to one profile every $333 \mathrm{~m}$. The vertical resolution of CALIOP varies with altitude - from $30 \mathrm{~m}$ in the lower troposphere, to $180 \mathrm{~m}$ in the stratosphere. For the PSC analyses, the CALIOP profile data are averaged to a spatial resolution of $180 \mathrm{~m}$ (vertical) and $5 \mathrm{~km}$ (horizontal).

\section{Observations and discussion}

\subsection{Meteorological situation}

The 2009/2010 Arctic winter lower stratosphere was unusually cold during the six-week period from mid-December 2009 until the end of January 2010. Among the Arctic winters of the past half century, the 2009/2010 Arctic winter was one of the few winters with synoptic-scale temperatures below the frost point, $T_{\text {frost }}$ (Pitts et al., 2011). During a seven-day period ending on 21 January, the vortex cooled below $T_{\text {frost }}$ over a large region between roughly $70-80^{\circ} \mathrm{N}$ and $10^{\circ} \mathrm{W}-80^{\circ} \mathrm{E}$. The vortex formed in early December, and a warming over Canada in mid-December caused a splitting of the vortex into two parts. The colder part of the vortex survived and cooled down through mid-January, reaching temperatures below $T_{\text {frost }}$. During this time period, orographic waves were frequently excited by the flow over Greenland, but even synoptic-scale temperatures were colder than $T_{\text {frost }}$; this is quite unusual for the Arctic and resulted in the formation of ice PSCs on large scales. A major warming around 24 January caused a displacement of the vortex to the Euro-

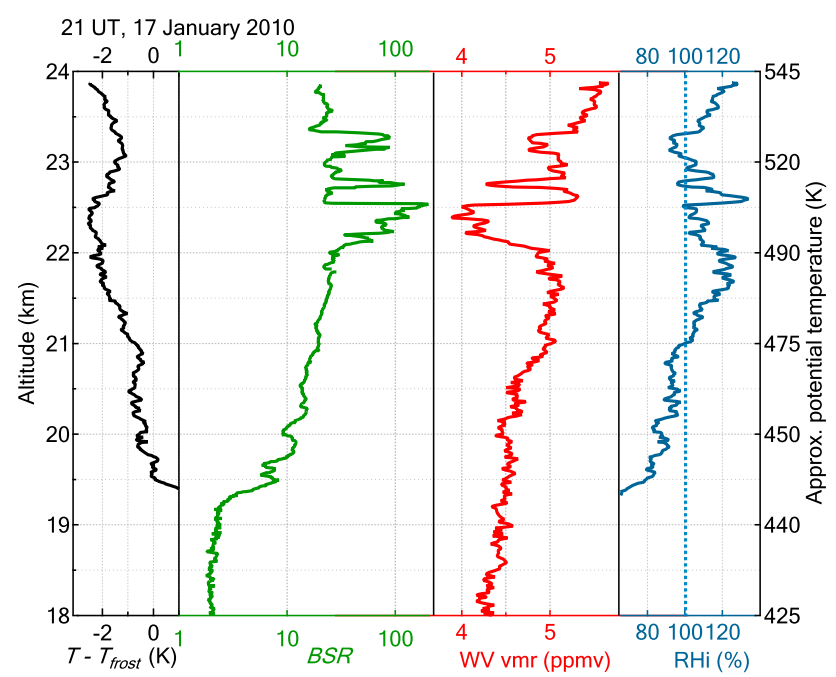

Fig. 1. Vertical profiles obtained during balloon descent on 17 January 2010. From left to right: difference between the observed temperature and the "climatological" frost point (based on January mean water vapour from FPH and CFH soundings in 2002-2010, black line); backscatter ratio at $870 \mathrm{~nm}$ (COBALD, green line); water vapour volume mixing ratio (FLASH-B, red line); relative humidity with respect to ice (based on water vapour from FLASH$\mathrm{B}$ and temperature from the RS92 Vaisala radiosonde). The time stamp in the upper-left corner refers to the time of stratospheric measurements.

pean Arctic and also initiated the breakup of the vortex. A detailed description of the Arctic winter 2009/2010 is provided by Dörnbrack et al. (2012) and Pitts et al. (2011).

\subsection{Ice PSC formation and water depletion}

The first balloon sounding from Sodankylä within the LAPBIAT-II campaign was carried out on 17 January. By that time, a large area north of Sodankylä had cooled below $T_{\text {frost }}$ at and above the $490 \mathrm{~K}$ potential temperature level, i.e. above $\sim 22 \mathrm{~km}$ altitude. The balloon payload included both FLASH-B and CFH hygrometers as well as the COBALD backscatter sonde. Figure 1 displays the vertical profiles of the $B S R$, water mixing ratio, and relative humidity with respect to ice $\left(\mathrm{RH}_{\text {ice }}\right.$ calculated from the measured mixing ratio and temperature). All profiles in Fig. 1 were taken during the descent under parachute with a rather low vertical speed of about $5 \mathrm{~m} \mathrm{~s}^{-1}$ due to incomplete burst of the balloon. Owing to the slow descent, the actual vertical resolution of the water vapour profile is about $20 \mathrm{~m}$. To provide a comparison with the climatological situation, the leftmost panel further shows the difference between the observed temperature and the "climatological" frost point, calculated using the January mean water vertical profile, obtained from the NOAA (National Oceanic and Atmospheric Administration) Frost Point Hygrometer (FPH) and CFH soundings at Sodankylä since 
2002 in the absence of ice clouds (see Supplement for details).

The $B S R$ profile displays three remarkable enhancements between 22 and $23.5 \mathrm{~km}$ (potential temperature 490-535 K). A layer between 22 and $22.5 \mathrm{~km}$ is characterized by a gradual increase of $B S R$ from 20 to nearly 200, followed by a sharp drop back to the value of 20 . Two additional enhancements of smaller vertical extent and with maximum $B S R$ values of about 50 were measured, centred at $22.7 \mathrm{~km}$ and $23.3 \mathrm{~km}$. The colour index in the 22-23.5 km layer (not shown), ranges from 7 to 14, pointing to supermicron particles. Most likely, the three layers of large $B S R$ and CI contain ice particles with radii larger than $\sim 2 \mu \mathrm{m}$. The ice layers are superimposed onto a broad layer of elevated backscatter values above $19.5 \mathrm{~km}$, most likely composed of liquid PSC particles or mixtures of liquid and NAT termed "STS" or "Mix-1", respectively, in the classification of Pitts et al. (2011).

The presence of ice clouds is strongly supported by the measured profile of water mixing ratios, showing a clear anti-correlation with $B S R$, with considerable reductions in mixing ratio (by up to $1.3 \mathrm{ppmv}$ ) inside the ice PSC layers, which results from repartitioning of gas-phase water into the solid phase. The precise altitude match of these layers in $B S R$ and mixing ratio, including fine details, is remarkable. Above $21 \mathrm{~km}(\sim 475 \mathrm{~K})$ the air is mostly supersaturated, as shown by the profile of $\mathrm{RH}_{\text {ice }}$. The maximum values of $\mathrm{RH}_{\text {ice }}$ are observed outside the ice layers with a peak value of $134 \%$ at $22.6 \mathrm{~km}$, just between the two layers of ice PSCs, whereas inside the ice clouds the $\mathrm{RH}_{\text {ice }}$ is in the range $90 \%-110 \%$. This is probably due to equilibration between the gas and condensed phase. Indeed, equilibration times for the water vapour condensing onto the ice particles are of the order of $\tau \sim 10^{3} \mathrm{~s} \times\left(1 \mu \mathrm{m} r_{\text {ice }}\right) \times\left(1 \mathrm{~cm}^{-3} n_{\text {ice }}\right)$ for monodisperse ice particles with radius $r_{\text {ice }}$ and number density $n_{\text {ice. }}$. As we show in the companion paper (Engel et al., 2013b), microphysical modelling suggests $r_{\text {ice }} \sim 10 \mu \mathrm{m}$ and $n_{\text {ice }} \sim 10^{-2} \mathrm{~cm}^{-3}$, i.e. $\tau \sim 3 \mathrm{~h}$ at the time it was measured in Sodankylä.

Important information is provided by the difference between the frost point temperature and the observed temperature $\left(T-T_{\text {frost }}^{\text {climatol }}\right)$. Temperatures $2 \mathrm{~K}$ below the climatological frost point are observed in a $1 \mathrm{~km}$ thick layer between 21.6 and $22.6 \mathrm{~km}$ with the absolute value reaching $2.5 \mathrm{~K}$ inside the thickest ice cloud between 22 and $22.5 \mathrm{~km}$. Trajectories backward and forward in time show that the air masses were in a continuous cooling phase. Details of trajectory calculations, the temperature evolution, and possible formation pathways of the observed PSC are provided by Engel et al. (2013b).

The balloon measurements on 17 January capture freshly formed layers of ice PSCs and concurrent uptake of water from the gas phase. In the following section, we will describe the evolution of the perturbed air masses based on the subsequent balloon soundings.

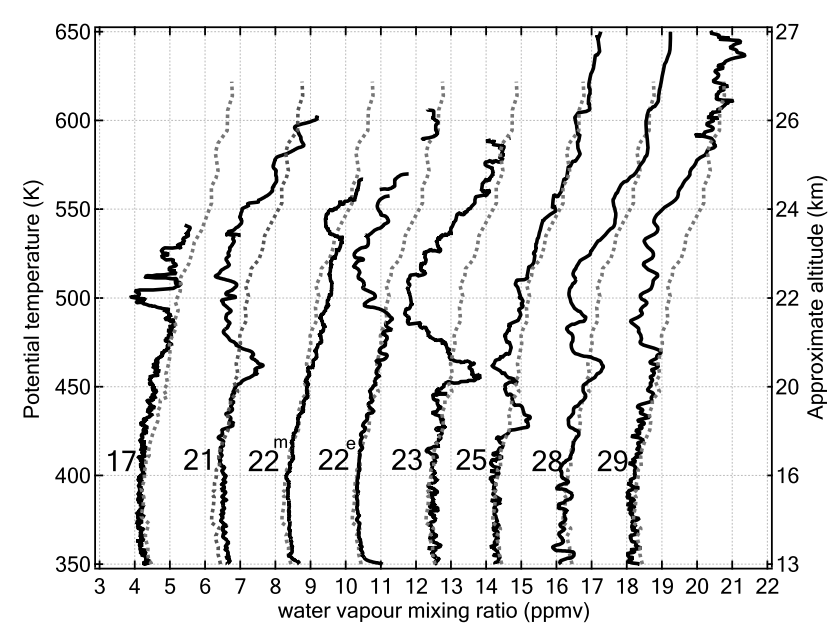

Fig. 2. Vertical profiles of water vapour obtained during January 2010 (solid black lines) compared against the "climatological" water vapour profile (based on January mean water vapour from FPH and CFH soundings at Sodankylä in 2002-2010, grey dashed lines). Successive profiles are shifted by 2 ppmv. The dates of the soundings are given on the left of each profile. The superscript indices " $\mathrm{m}$ " and "e" indicate respectively morning and evening soundings on 22 January. The profiles of 17, 25, 28 and 29 January were obtained using FLASH-B, the remaining profiles were obtained using CFH.

\subsection{Irreversible dehydration and rehydration}

Evidence of irreversible dehydration is provided by the subsequent water vapour profiles, shown in Fig. 2 (see also Fig. S1 in the Supplement for detailed information on selected soundings, including the backscatter profiles, and Table 1 for a summary of all soundings). While all the backscatter profiles obtained after 17 January suggested an absence of ice particles (as inferred from the fact that the values of $B S R$ do exceed 20), the water vapour profiles reveal a persistent reduction in mixing ratio at different levels above $19.5 \mathrm{~km}$ (450 K).

The sounding performed on 21 January exhibits a broad layer between 470 and $570 \mathrm{~K}$ ( 21 and $24.5 \mathrm{~km}$ ), where water vapour is depleted by up to $0.7 \mathrm{ppmv}$ and, below, a narrower layer - between 450 and $470 \mathrm{~K}(20$ and $21 \mathrm{~km})$ - of enhanced vapour mixing ratio by $0.6 \mathrm{ppmv}$. The observed vertical structure suggests a removal of water from the upper layer through gravitational settling of ice particles, followed by these particles' sublimation below at higher temperatures (rehydration). Note that advection of extra-vortex air as a reason for local reductions in water mixing ratios (as reported by e.g. Müller et al., 2003) can be ruled out, given the strength of the vortex at that time. Another indication of the inner-vortex origin of the water-depleted air masses is provided by the trajectory analysis performed using the Lagranto model (Wernli and Davies, 1997) initialized by ECMWF (European Centre of Medium-Range Weather Forecasts) reanalysis. The 7-day 
backward trajectories showed that the air masses sampled on 21 January were following the vortex rotation and passing an area of sub-frost point temperatures between Scandinavia and Spitsbergen on 16 January. The respective observations by CALIOP indicated a widespread occurrence of ice PSCs in this region, extending between 20 and $25 \mathrm{~km}$ altitude (Pitts et al., 2011, Supplement), which is consistent with the vertical range of the dehydrated layer.

The next sounding, performed $19 \mathrm{~h}$ later in the early morning on 22 January (marked $22^{\mathrm{m}}$ in Fig. 2), revealed a remarkable change in water vertical distribution, with a narrow dehydrated layer between 540 and $555 \mathrm{~K}$ (23.5 and $24 \mathrm{~km}$ ) and an absence of rehydration signatures, indicating the arrival of a new patch of perturbed air masses. A significant vertical enlargement of the water-depleted layer is revealed by the profile obtained $15 \mathrm{~h}$ later $\left(22^{\mathrm{e}}\right.$ in Fig. 2), showing the lower boundary of dehydration signal at $490 \mathrm{~K}(22 \mathrm{~km})$. Remarkably, neither 22 January sounding shows rehydration signatures similar to those observed on 21 January. This can be explained by the positive vertical wind shear (reported by the radiosondes), making the lower levels travel around the vortex more slowly (see also Engel et al., 2013b).

The effect of wind shear is clearly demonstrated by the sequence of successive $22^{\mathrm{m}}$ (morning), $22^{\mathrm{e}}$ (evening) and 23 January profiles, showing the dehydrated layer broadening and spreading towards the lower levels. The rehydrated air masses travelling at the lower levels and thus arriving at the sounding location later appear only in the 23 January profile, the one providing the most prominent evidence of the water vertical redistribution. Figure 3 shows the details of this sounding, represented by the vertical profiles of frost point difference, $B S R$, water mixing ratio and $\mathrm{RH}_{\text {ice }}$. The excursion of temperature below the "climatological" frost point is still visible in a layer between 20 and $24 \mathrm{~km}$, where the frost point difference reaches $2.8 \mathrm{~K}$. These conditions would likely cause formation of ice in an unperturbed stratosphere. However, as shown by the water mixing ratio profile, the stratospheric layer between 21 and $24 \mathrm{~km}$ is already dehydrated by $1.6 \mathrm{ppmv}$. Hence, $\mathrm{RH}_{\text {ice }}$ does not exceed $120 \%$ (at the coldest point of $183 \mathrm{~K}$ ). Importantly, despite the extremely low temperatures, the $B S R$ profiles indicate only moderate concentration of particles approaching the background state above $22 \mathrm{~km}(500 \mathrm{~K})$, which suggests that these layers are also denitrified. This is consistent with Khosrawi et al. (2011), who reported the onset of denitrification in early January and a fast decrease of $\mathrm{HNO}_{3}$ from 12 ppbv down to 5 ppbv at the $480 \mathrm{~K}$ level during the first half of January, as inferred from Aura MLS observations.

A totally different regime is represented by the layer below - between 450 and $460 \mathrm{~K}$ (19.7 and $20.6 \mathrm{~km}$ ) - which shows an enhancement in water mixing ratios of about $1 \mathrm{ppmv}$ that can be unambiguously associated with rehydration. This layer is also characterized by enhanced $B S R$ with values reaching 20, which is indicative of a cloud and a local $\mathrm{RH}_{\text {ice }}$ maximum of $116 \%$. The $B S R$ values are an order of mag-

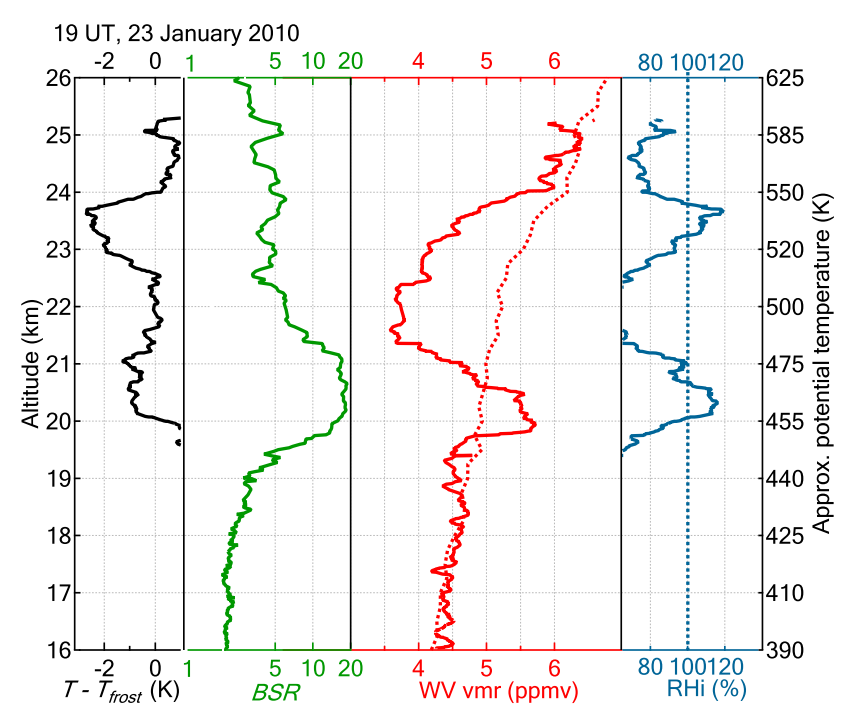

Fig. 3. Vertical profiles obtained during balloon ascent on 23 January 2010. From left to right: difference between the observed temperature and the "climatological" frost point (based on January mean water vapour from FPH and CFH soundings in 2002-2010, black line); backscatter ratio at $870 \mathrm{~nm}$ (green); water mixing ratio $(\mathrm{CFH})$, with climatological mean shown as dotted line (red); relative humidity with respect to ice (blue). Note the different vertical and horizontal scaling compared to Fig. 1. The time stamp in the upper-left corner refers to the time of stratospheric measurements.

nitude smaller than those observed on 17 January and, although it is not possible to draw a definitive conclusion about the type of this cloud from the COBALD data alone, it is most likely an STS PSC, possibly externally mixed with NAT particles at low number densities (classes "STS" or "Mix1 " in the terminology of Pitts et al. (2011), previously also called "type I PSCs"). Indeed, the CALIOP observations suggest widespread occurrence of STS clouds (Pitts et al., 2011, Fig. 16 and Supplement) without any indications of ice.

The vortex breakup followed by a major warming began around the 24 January (Dörnbrack et al., 2012). The sounding carried out $30 \mathrm{~h}$ later on 25 January (see Fig. 2 and Fig. S1) showed a further descent of dehydration and rehydration signatures, occurring at $460 \mathrm{~K}(20 \mathrm{~km})$ and $430 \mathrm{~K}(18.3 \mathrm{~km})$, respectively; lower $B S R$ values (reaching 10), and a warmer temperature minimum of $187 \mathrm{~K}$ at $22 \mathrm{~km}(515 \mathrm{~K})$. The minimum temperature increased further (to $191 \mathrm{~K}$ ) by the time of the subsequent sounding on 28 January, showing no indications of PSCs. The water vapour profile, however, still displays a remarkable dehydration signal between 470 and $550 \mathrm{~K}$ (20 and $22.5 \mathrm{~km}$ ) of 1 ppmv amplitude and a subtle rehydration signature at $460 \mathrm{~K}(19.5 \mathrm{~km})$. The next sounding, performed $24 \mathrm{~h}$ later on 29 January, revealed further warming, absence of clouds and a very similar dehydration signal in the same layer but without a rehydration signature at lower levels. An enhancement of water mixing ratios above $24 \mathrm{~km}$ 
might be indicative of the strong downwelling of moist air masses from the middle and upper stratosphere, which is a characteristic feature of major warmings. The three subsequent soundings, conducted in early February, indicated an absence of PSCs and a further gradual warming and descent of the temperature minimum amounting to $202 \mathrm{~K}$ at $19 \mathrm{~km}$ $(463 \mathrm{~K})$ on 06 February. The signatures of water redistribution could still be detected on 3 and 6 February, but with perturbations of decreasing amplitude, likely due to a dispersion of the perturbed air masses in the vortex.

A summary of the water vapour and aerosol soundings conducted during the first phase of the LAPBIAT-II campaign is provided in Table 1, including the information on the observed PSCs, and de- and rehydration signatures and their amplitudes. The table shows that the dehydration signal was observed in all soundings except those conducted on 20 January and 2 February, whereas the rehydration signal appears in 5 out of 13 soundings only, namely those conducted on 21, 23, 25 and 28 January as well as that conducted on 6 February. Although the very first sounding, conducted on 17 January, showed a reduction of water vapour in the presence of ice, the evidence of permanent removal of water is demonstrated by the subsequent soundings only, showing depleted water in the absence of ice clouds. The maximum amplitude of water depletion amounts to $1.6 \mathrm{ppmv}$, which is comparable to the few previous observations of dehydration in the Arctic (quoted above), except the historical observation in the Arctic by Vömel et al. (1997), who reported a reduction in the water mixing ratio of up to $2.5 \mathrm{ppmv}$. In contrast, signatures of rehydration and the coherent relationship between de- and rehydration in the winter Arctic stratosphere have been observed for the first time.

\subsection{Spatiotemporal evolution of dehydration}

The balloon soundings represent high-resolution snapshots of the vertical water redistribution measured above a single location. We will further examine the global spatiotemporal evolution of ice PSCs and concurrent dehydration using space-borne observations of scattering ratios and water mixing ratios provided by CALIOP and Aura MLS, respectively.

Figure 4 displays a series of polar projection maps of daily averaged water mixing ratios on the $490 \mathrm{~K}$ potential temperature measured by Aura MLS during the second half of January 2010. Superimposed on these maps are the observations of ice PSCs by CALIOP: the vortex boundary (defined as the potential vorticity (PV) contour of $35 \times 10^{-6} \mathrm{~K} \mathrm{~m}^{2} \mathrm{~kg}^{-1} \mathrm{~s}^{-1}$ ), and the $187 \mathrm{~K}$ temperature contour, corresponding to the frost point at $30 \mathrm{hPa}$ (corresponding roughly to $490 \mathrm{~K}$ potential temperature). The map of 15 January shows an area of mixing ratio reduced below 4.5 ppmv north-west from Scandinavia inside the frost point contour. As expected, the occurrence of ice is confined to the area colder than $T_{\text {frost }}$. The area of sub-frost point temperatures and ice clouds expands and moves eastward, ap- proaching Sodankylä on 17 January. The daily-averaged water vapour field on 17 January from MLS does not yet show the signature of water depletion directly above Sodankylä, but further north, whereas the balloon measurements acquired late on the same day (at 21:00 UT) revealed the onset of dehydration, as discussed above. The situation on 18 January indicates a further expansion of the cold pool of $T<T_{\text {frost }}$ reaching the sounding location and comprising a large area of depleted water mixing ratios as low as 3.5 ppmv northeast from Scandinavia, centred above the island of Novaya Zemlya. An occurrence of synoptic-scale ice PSCs, covering several millions of square kilometres within the cold pool, is observed by CALIOP. Remarkably, the area of water depletion extends outside the area of temperatures below the frost point, unambiguously demonstrating irreversible dehydration. The observations of 19 January exhibit essentially the same picture as they did on the previous day, but with less ice PSCs and a smaller horizontal extent of cold and dehydrated pools. In contrast, the dehydrated air masses that have been advected outside the cold area gain a larger spatial extent.

Over the next few days, the dehydrated pool elongated and travelled around the centre of vortex, passing across the pole (beyond MLS coverage) during 21-22 January and reappearing above northern Scandinavia by 23 January. The balloon sounding conducted in the late afternoon on 23 January displayed the largest amplitude of dehydration, which is consistent with the MLS observations, which show the dry pool approaching the sounding location on 23 January and fully covering Sodankylä on 24 January.

On 24 January, due to a planetary wave event, the vortex began to lose its symmetry and the cold region progressively shifted away from the vortex centre (Dörnbrack et al., 2012). Meanwhile, the trace of dehydrated air masses became less discernible in the satellite images due to mixing with non-dehydrated air inside the vortex. The pool of mixing ratios below 4.5 ppmv passed across northwest Russia on 25 January, further elongating and dissipating along the southeast boundary of the vortex. The final indications of the air patches dehydrated below 4.5 ppmv appear during 28 29 January, after their second circuit within the vortex. On 28 January the dry pool is partly obscured by the MLS polar "blind spot", and on 29 January it emerges above Scandinavia. Consistent with that, the balloon soundings of 28 and 29 January show the dehydration signal of $0.7-0.8 \mathrm{ppmv}$ maximum amplitude.

Whereas the spatial evolution of the dehydrated pool observed by MLS is consistent with the picture provided by the balloon soundings, one should consider the limited sampling density of MLS measurements and their broad vertical resolution, which may impede the observation of weaker dehydration signals. Thus, the movement of the largest dehydrated pool, which arose during 17-19 January, is easily discernable on the polar projections, whereas the smaller patches of dehydrated air, processed by the sub-frost point 

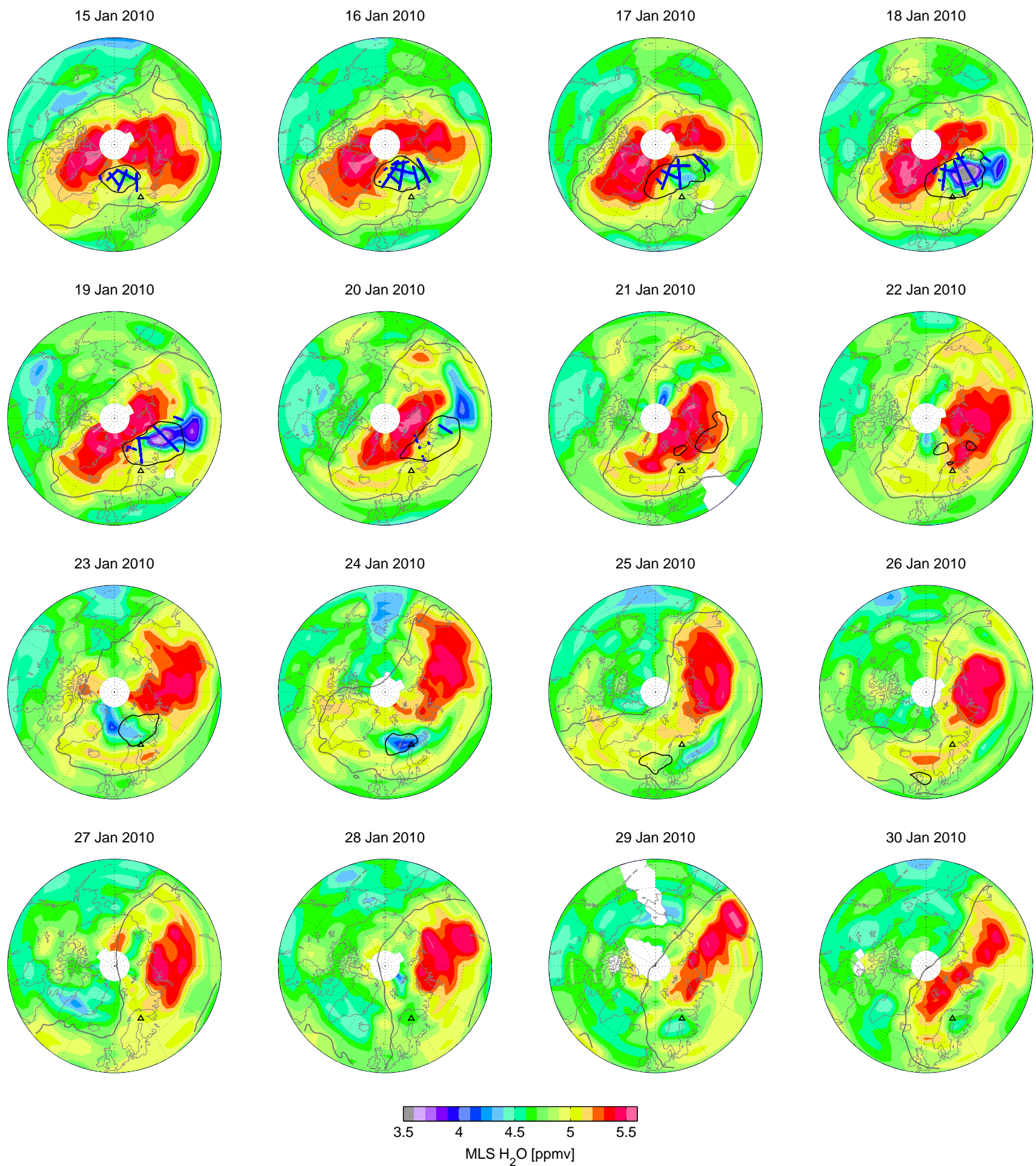

Fig. 4. Aura MLS polar projection maps of water vapour mixing ratio for $15-30$ January 2010, interpolated onto the $490 \mathrm{~K}$ potential temperature surface. Grey contour denotes the vortex boundary given as the potential vorticity value of $35 \times 10^{-6} \mathrm{~K} \mathrm{~m}^{2} \mathrm{~kg}^{-1} \mathrm{~s}^{-1} \mathrm{Black}$ contour: $187 \mathrm{~K}$ at 00:00 UTC $T_{\text {frost }}$ at $30 \mathrm{hPa}$, assuming 5 ppmv of water vapour). Blue markers: CALIOP observations of ice clouds thicker than $540 \mathrm{~m}$ in the $20-24 \mathrm{~km}$ altitude range. Balloon sounding location is marked with a black triangle. 
Table 2. Listing of aircraft flights during January-February 2010 (RECONCILE first phase). From left to right: date and time of the aircraft takeoff; hygrometer type used (FLA=FLASH-A); indicator of rehydration signatures; maximum amplitude of rehydration signal (ppmv).

\begin{tabular}{lclrr}
\hline Date & Time, UTC & Hygrometer & Indicator & Amplitude \\
\hline 17.01 .2010 & $11: 17$ & FISH, FLA & - & - \\
20.01 .2010 & $08: 13$ & FISH & - & - \\
22.01 .2010 & $10: 01$ & FISH, FLA & - & - \\
24.01 .2010 & $13: 30$ & FISH, FLA & - & - \\
25.01 .2010 & $05: 50$ & FISH, FLA & $\mathrm{R}$ & $+(0.3-0.7)$ \\
28.01 .2010 & $09: 00$ & FISH, FLA & $\mathrm{R}$ & +0.6 \\
30.01 .2010 & $06: 36$ & FISH, FLA & - & - \\
02.02 .2010 & $10: 01$ & FISH, FLA & - & - \\
\hline
\end{tabular}

temperatures during the preceding days (as detected in the 21 January sounding) are far less obvious. The $3 \mathrm{~km}$ vertical resolution of MLS does not allow tracking the rehydration signatures of $\sim 1 \mathrm{~km}$ thickness as shown by the balloon soundings. In addition, the rehydration signal could be smeared out by the dehydration signal immediately above; therefore both signals weaken one another.

\subsection{Evidence of dehydration and rehydration from aircraft measurements}

The $20 \mathrm{~km}$ ceiling altitude of the M55-Geophysica aircraft carrying the RECONCILE payload did not allow for sampling the dehydrated air masses, which, according to the balloon soundings, were mostly restricted to the altitudes above $20 \mathrm{~km}(475 \mathrm{~K})$. However, the rehydrated plumes, detected in the balloon soundings as low as $18 \mathrm{~km}$, were within reach of the aircraft. A summary of the aircraft flights and the rehydration signatures detected therein is provided in Table 2.

Enhancements in the water vapour mixing ratio by $0.3-$ 0.9 ppmv were detected in the aircraft flights on 25 and 28 January; consistent with the balloon profiles obtained on the same day and showing the rehydrated layers. Figure 5 displays the time series of water vapour measured by the FISH and FLASH-A instruments on the flight of 25 January, the climatological January mean water vapour for the given altitude (based on balloon soundings at Sodankylä in 20022010), the potential temperature and the altitude flight profile. The time series of water vapour provided by the two aircraft hygrometers are in good agreement (see supplementary material for details), although the FISH and FLASH-A water vapour time series are both 5-8\% drier than the climatological mean.

During the horizontal flight leg conducted at constant altitude of $19 \mathrm{~km}$, water vapour enhancements of $0.5,0.3$ and 0.7 ppmv were observed within the time intervals 24900 $25200,25680-25900$ and 28 000-28 470 s, corresponding respectively to 58,42 and $81 \mathrm{~km}$ horizontal crosscut distances (marked by 3 black arrows). The water enhancements

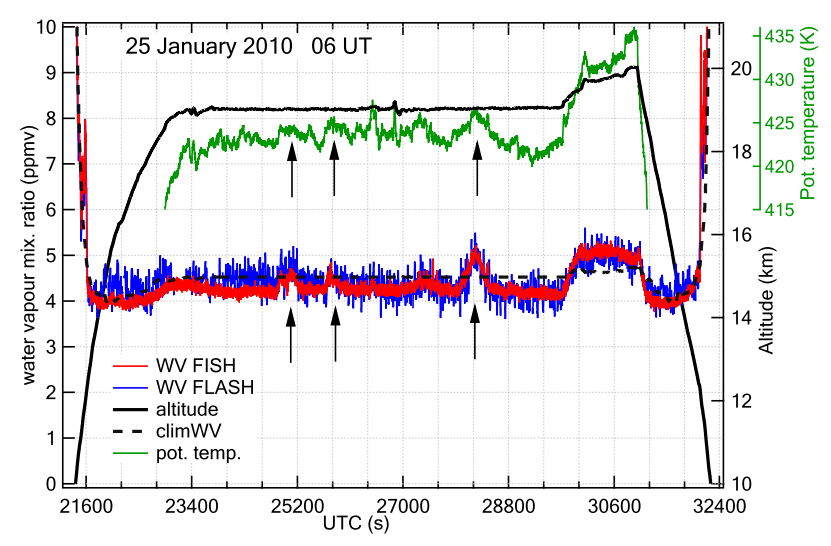

Fig. 5. Results of the aircraft flight on 25 January 2010 showing the rehydration signatures: time series of water mixing ratio measured by FISH and FLASH-A (left axis); potential temperature (upper right axis); altitude flight profile (right axis) and climatological mean water vapour for the given altitude (based on January mean water vapour from FPH and CFH soundings in 2002-2010, dashed black line, left axis). Tick marks on the horizontal axis correspond to $10 \mathrm{~min}$ intervals. The black arrows point to regions with positive water vapour anomalies, associated with rehydration.

coincide with local maxima in potential temperature, suggesting that the aircraft was flying just at the lower edge of a rehydrated layer, crossing three troughs of it, which were bulging down and intersecting the aircraft flight level. This is confirmed by a larger enhancement of the water mixing ratio (by 1 ppmv) detected once the aircraft started climbing to its ceiling altitude of $20 \mathrm{~km}$. An increase of $1 \mathrm{ppmv}$ within a $1 \mathrm{~km}$ layer significantly exceeds the expected vertical gradient of mixing ratio inside the vortex, as seen from the climatological mean water vapour (dashed black curve), displaying a difference of only $0.3 \mathrm{ppmv}$ between 19 and $20 \mathrm{~km}$. Furthermore, at the highest part of the flight, the water vapour series show a small drop of $0.3 \mathrm{ppmv}$, which could be due to the aircraft approaching the top of the rehydrated layer. Such a vertical structure is consistent with the balloon profile of 25 January, taken $7 \mathrm{~h}$ prior to the aircraft flight and displaying the rehydrated layer between $18.2 \mathrm{~km}(430 \mathrm{~K})$ and $19 \mathrm{~km}$ (440 K).

Similar features were observed in the aircraft flight on 28 January (not shown), when both hygrometers detected an increase of $0.5-0.6 \mathrm{ppmv}$ at $19 \mathrm{~km}$ during the final climb of the aircraft to $20 \mathrm{~km}$ altitude, followed by a drop of water vapour to its background level at the aircraft ceiling point. This observation is consistent with the balloon profile obtained $6 \mathrm{~h}$ later from Sodankylä, which showed a rehydrated layer with a 0.5 ppmv water enhancement between 19 and $19.5 \mathrm{~km}$ altitude. 


\section{Summary and conclusions}

By 15 January 2010, the coldest regions of the Arctic stratospheric vortex reached temperatures as low as $T_{\text {frost }}$. This was accompanied by a major outbreak of ice PSCs, observed by CALIOP on a synoptic scale, lasting from 15 to 21 January (Pitts et al., 2011). Owing to the extensive sounding program implemented within the LAPBIAT-II and EU RECONCILE campaigns, the composition of the Arctic stratosphere during this period was accurately monitored using stratospheric balloons and the high-altitude M55-Geophysica aircraft.

Thirteen balloon soundings were conducted from Sodankylä during 17 January-6 February, involving CFH and FLASH-B hygrometers flown together with the COBALD backscatter sonde. The measurements of water vapour, obtained using two independent techniques, are in excellent agreement, which allows for using FLASH-B and CFH profiles as consistent and interchangeable data sets. The balloon measurements taken on 17 January capture freshly formed layers of ice PSC and concurrent uptake of water from the gas phase in great detail, providing an unprecedented highresolution "snapshot" of the process of ice PSC formation. Possible formation pathways of the observed PSC are discussed in the companion paper by Engel et al. (2013b). Furthermore, balloon soundings provided evidence of irreversible dehydration by showing a permanent layer of reduced water mixing ratio between 19.5 and $24 \mathrm{~km}$ altitude in the absence of ice PSCs as well as an underlying $1 \mathrm{~km}$ thick layer of enhanced water mixing ratio, attributed to rehydration through evaporation of the falling ice particles. The vertical redistribution of water vapour is observed for the first time in the Arctic stratosphere. The signatures of dehydration and rehydration in the vertical profiles could be detected until 6 February, although the amplitude of perturbations decreased over time due to continuing dispersal of the air masses in the vortex. Additional evidence of the existence of rehydrated layers is provided by the aircraft-borne FISH and FLASH-A hygrometers, on board by the stratospheric research aircraft M55-Geophysica in two of the eight aircraft flights carried out during the given period. The airborne hygrometers, being in good agreement with each other, show enhancements in mixing ratio of $0.3-0.7$ ppmv between 19 and $20 \mathrm{~km}$ altitude, which is consistent with measurements from the corresponding balloon flights. In contrast, the dehydrated layers, residing above the aircraft ceiling altitude could not be sampled by the airborne instruments.

The source region of dehydration and its spatiotemporal evolution was examined using space-borne Aura MLS water vapour observations. A sequence of polar projection water vapour maps shows the onset of dehydration on 15 January and its maximum development on 18-19 January, when the dehydrated pool extends outside the area below the frost point. The dehydrated air masses travel around the centre of the vortex, reappearing above Scandinavia on 22 January. The final indications of patches of air dehydrated below 4.5 ppmv appear on 28-29 January, after their second circuit within the vortex. The spatial evolution of the dehydrated pool observed by MLS is consistent with the picture provided by the balloon soundings, although due to $\sim 3 \mathrm{~km}$ vertical resolution of MLS measurements the dehydration signal could be smeared out by the rehydration signal immediately below it, resulting in a weakening of both signals. In particular, the evolution of the $1 \mathrm{~km}$-thick rehydration layer could not be followed by MLS.

Overall, the consistent observations of water vapour from balloon, aircraft and satellite platforms together with the aerosol observations by COBALD and CALIOP provide a comprehensive view of the consequences of the widespread ice PSC occurrence, that is:

1. formation of a dehydrated layer at $19.5-24 \mathrm{~km} \mathrm{(450-}$ $550 \mathrm{~K}$ ) with a reduction in water mixing ratios of up to $1.6 \mathrm{ppmv}$;

2. formation of a rehydrated layer at $18-20.5 \mathrm{~km}$ $(430-460 \mathrm{~K})$ with mixing ratio enhancements up to $0.9 \mathrm{ppmv}$;

3. redistribution of water within $18-24 \mathrm{~km}$ due to gravitational settling and subsequent evaporation of ice particles.

Such exceptional conditions in the Arctic stratosphere have been observed for the first time. These observations represent the most accurate and detailed data set on water vapour redistribution in the stratospheric vortex ever recorded.

\section{Supplementary material related to this article is available online at http://www.atmos-chem-phys.net/13/ 11503/2013/acp-13-11503-2013-supplement.pdf.}

Acknowledgements. We thank the personnel of the FMI-ARC and RECONCILE coordination teams and the Myasischev Design Bureau. Through the same contract, the aircraft campaign in Kiruna and I. Engel and F. Wienhold, were partially funded by the EC as part of the FP7 project RECONCILE (226365-FP7-ENV-2008-1). The balloon campaign in Sodankylä was partly funded by the Lapland Atmosphere-Biosphere Facility (LAPBIAT). Stratospheric water vapour research in the FMI was supported by Finnish Academy under grant no. 140408. The work was partly funded by the Russian Foundation for Basic Research grants 12-05-31384Mol-a and 11-05-00475-a. Work at the Jet Propulsion Laboratory, California Institute of Technology, was done under contract with the National Aeronautics and Space Administration.

Edited by: G. Vaughan 


\section{References}

Bertaux, J. L. and Delannoy, A.: Premieres measures stratospheriques par un hygrometre a fluorescence ultraviolette, C. R. Acad. Sc. Paris, 286, 191-194, 1978.

Beyerle, G., Gross, M., Haner, D., Kjome, N., McDermid, I., McGee, T., Rosen, J., Schäfer, H.-J., and Schrems, O.: A lidar and backscatter sonde measurement campaign at Table Mountain during February-March 1997: Observations of cirrus clouds, J. Atmos. Sci., 58, 1275-1287, 2001.

Biermann, U. M., Crowley, J. N., Huthwelker, T., Moortgat, G. K., Crutzen, P. J., and Peter, T.: FTIR studies on lifetime prolongation of stratospheric ice particles due to NAT coating, Geophys. Res. Lett., 25, 3939-3942, doi:10.1029/1998GL900040, 1998.

Brabec, M., Wienhold, F. G., Luo, B. P., Vömel, H., Immler, F., Steiner, P., Hausammann, E., Weers, U., and Peter, T.: Particle backscatter and relative humidity measured across cirrus clouds and comparison with microphysical cirrus modelling, Atmos. Chem. Phys., 12, 9135-9148, doi:10.5194/acp-12-9135-2012, 2012.

Bukowiecki, N., Zieger, P., Weingartner, E., Jurányi, Z., Gysel, M., Neininger, B., Schneider, B., Hueglin, C., Ulrich, A., Wichser, A., Henne, S., Brunner, D., Kaegi, R., Schwikowski, M., Tobler, L., Wienhold, F. G., Engel, I., Buchmann, B., Peter, T., and Baltensperger, U.: Ground-based and airborne in-situ measurements of the Eyjafjallajökull volcanic aerosol plume in Switzerland in spring 2010, Atmos. Chem. Phys., 11, 10011-10030, doi:10.5194/acp-11-10011-2011, 2011.

Dörnbrack, A., Leutbecher, M., Kivi, R., and E. Kyrö: Mountain wave induced record low stratospheric temperatures above northern Scandinavia, Tellus Ser. A, 51, 951-963, 1999.

Dörnbrack, A., Pitts, M. C., Poole, L. R., Orsolini, Y. J., Nishii, K., and Nakamura, H.: The 2009-2010 Arctic stratospheric winter general evolution, mountain waves and predictability of an operational weather forecast model, Atmos. Chem. Phys., 12, 36593675, doi:10.5194/acp-12-3659-2012, 2012.

Drdla, K. and Turco, R. P.: A 1-D model incorporating temperature oscillations, J. Atmos. Chem., 12, 319-366, 1991.

Engel, I., Luo, B. P., Pitts, M. C., Poole, L. R., Hoyle, C. R., Grooß, J.-U., Dörnbrack, A., and Peter, T.: Heterogeneous formation of polar stratospheric clouds - Part 2: Nucleation of ice on synoptic scales, Atmos. Chem. Phys., 13, 10769-10785, doi:10.5194/acp13-10769-2013, 2013a.

Engel, I., Luo, B. P., Khaykin, S. M., Wienhold, F. G., Vömel, H., Kivi, R., Hoyle, C. R., Grooß, J.-U., Pitts, M. C., and Peter, T.: Arctic stratospheric dehydration - Part 2: Microphysical modeling, Atmos. Chem. Phys. Discuss., 13, 27163-27200, doi:10.5194/acpd-13-27163-2013, 2013 b.

Fahey, D. W., Kelly, K. K., Kawa, S. R., Tuck, A. F., Loewenstein, M., Chan, K. R., and Heidt, L. E.: Observations of denitrification and dehydration in the winter polarstratosphere, Nature, 344, 321-324, 1990.

Fueglistaler, S., Buss, S., Luo, B. P., Wernli, H., Flentje, H., Hostetler, C. A., Poole, L. R., Carslaw, K. S., and Peter, Th.: Detailed modeling of mountain wave PSCs, Atmos. Chem. Phys., 3, 697-712, doi:10.5194/acp-3-697-2003, 2003.

Hintsa, E. J., Newman, P. A., Jonsson, H. H., Webster, C. R., May, R. D., Herman, R. L., Lait, L. R., Schoeberl, M. R., Elkins, J. W., Wamsley, P. R., Dutton, G. S., Bui, T. P., Kohn, D. W., and Anderson, J. G.: Dehydration and denitrification in the Arctic polar vortex during the 1995-1996 winter, Geophys. Res. Let., 25, 501-504, 1998.

von Hobe, M., Bekki, S., Borrmann, S., Cairo, F., D’Amato, F., Di Donfrancesco, G., Dörnbrack, A., Ebersoldt, A., Ebert, M., Emde, C., Engel, I., Ern, M., Frey, W., Genco, S., Griessbach, S., Grooß, J.-U., Gulde, T., Günther, G., Hösen, E., Hoffmann, L., Homonnai, V., Hoyle, C. R., Isaksen, I. S. A., Jackson, D. R., Jánosi, I. M., Jones, R. L., Kandler, K., Kalicinsky, C., Keil, A., Khaykin, S. M., Khosrawi, F., Kivi, R., Kuttippurath, J., Laube, J. C., Lefèvre, F., Lehmann, R., Ludmann, S., Luo, B. P., Marchand, M., Meyer, J., Mitev, V., Molleker, S., Müller, R., Oelhaf, H., Olschewski, F., Orsolini, Y., Peter, T., Pfeilsticker, K., Piesch, C., Pitts, M. C., Poole, L. R., Pope, F. D., Ravegnani, F., Rex, M., Riese, M., Röckmann, T., Rognerud, B., Roiger, A., Rolf, C., Santee, M. L., Scheibe, M., Schiller, C., Schlager, H., Siciliani de Cumis, M., Sitnikov, N., Søvde, O. A., Spang, R., Spelten, N., Stordal, F., Sumin'ska-Ebersoldt, O., Ulanovski, A., Ungermann, J., Viciani, S., Volk, C. M., vom Scheidt, M., von der Gathen, P., Walker, K., Wegner, T., Weigel, R., Weinbruch, S., Wetzel, G., Wienhold, F. G., Wohltmann, I., Woiwode, W., Young, I. A. K., Yushkov, V., Zobrist, B., and Stroh, F.: Reconciliation of essential process parameters for an enhanced predictability of Arctic stratospheric ozone loss and its climate interactions (RECONCILE): activities and results, Atmos. Chem. Phys., 13, 92339268, doi:10.5194/acp-13-9233-2013, 2013.

Hoyle, C. R., Engel, I., Luo, B. P., Pitts, M. C., Poole, L. R., Grooß, J.-U., and Peter, T.: Heterogeneous formation of polar stratospheric clouds - Part 1: Nucleation of nitric acid trihydrate (NAT), Atmos. Chem. Phys., 13, 9577-9595, doi:10.5194/acp13-9577-2013, 2013.

Jiménez, C., Pumphrey, H. C., MacKenzie, I. A., Manney, G. L., Santee, M. L., Schwartz, M. J., Harwood, R. S., and Waters, J. W.: EOS MLS observations of dehydration in the 2004-2005 polar winters, Geophys. Res. Lett., 33, L16806, doi:10.1029/2006GL025926, 2006.

Khosrawi, F., Urban, J., Pitts, M. C., Voelger, P., Achtert, P., Kaphlanov, M., Santee, M. L., Manney, G. L., Murtagh, D., and Fricke, K.-H.: Denitrification and polar stratospheric cloud formation during the Arctic winter 2009/2010, Atmos. Chem. Phys., 11, 8471-8487, doi:10.5194/acp-11-8471-2011, 2011.

Kivi, R., Kyrö, E., Dörnbrack, A., and Birner, T.: Observations of vertically thick polar stratospheric clouds and record low temperature in the Arctic vortex, Geophys. Res. Let., 28, 3661-3664, 2001.

Kivi, R., Vömel, H., Immler, F., Lehtola, T., Kämpfer, N., Straub, C., Yushkov, V., Khaykin, S., Christensen, T., and Wienhold, F. G.: LAPBIAT Atmospheric Sounding Campaign in 2010, Upper-Air and Remote Sensing Observations of Water Vapour, In: WMO Technical Conference on Meteorological and Environmental Instruments and Methods of Observation (TECO-2010), Helsinki, Finland, 30 August-1 September 2010, Instruments and Observing System Methods Report No. 104, WMO/TD-No. 1546, 2010.

Kley, D. and Stone, E. J.: Measurements of water vapour in the stratosphere by photodissotiation with Ly- $\alpha(1216 \mathrm{~A})$ light, Rev. Sci. Instrum., 49, 661-697, 1978.

Koop, T., Biermann, U. M., Raber, W., Luo, B. P., Crutzen, P. J., and Peter, T.: Do stratospheric aerosol droplets freeze above the ice frost point?, Geophys. Res. Lett., 22, 917-920, 1995. 
Larsen, N., Knudsen, B. M., Svendsen, S. H., Deshler, T., Rosen, J. M., Kivi, R., Weisser, C., Schreiner, J., Mauerberger, K., Cairo, F., Ovarlez, J., Oelhaf, H., and Spang, R.: Formation of solid particles in synoptic-scale Arctic PSCs in early winter 2002/2003, Atmos. Chem. Phys., 4, 2001-2013, doi:10.5194/acp-4-20012004, 2004.

Livesey, N. J., Read, W. G., Froidevaux, L., Lambert, A., Manney, G. L., Pumphrey, H. C., Santee, M. L., Schwartz, M. J., Wang, S., Cofield, R. E., Cuddy, D. T., Fuller, R. A., Jarnot, R. F., Jiang, J. H., Knosp, B. W., Stek, P. C., Wagner, P. A., and Wu, D. L.: Aura Microwave Limb Sounder (MLS) Version 3.3 Level 2 data quality and description document, JPL D-33509, available at:http://mls.jpl.nasa.gov/, 2011.

Maturilli, M. and A. Dörnbrack: Polar stratospheric ice cloud above Spitsbergen, J. Geophys. Res., 111, D18210, doi:10.1029/2005JD006967, 2006.

Müller, M., Neuber, R., Fierli, F., Hauchecorne, A., Vömel, H., and Oltmans, S. J.: Stratospheric water vapour as tracer for Vortex filamentation in the Arctic winter 2002/2003, Atmos. Chem. Phys., 3, 1991-1997, doi:10.5194/acp-3-1991-2003, 2003.

Nedoluha, G. E., Bevilacqua, R. M., Hoppel, K. W., Daehler, M., Shettle, E. P., Hornstein, J. H., Fromm, M. D., Lumpe, J. D., and Rosenfield, J. E.: POAM III measurements of dehydration in the Antarctic lower stratosphere, Geophys. Res. Lett., 27, 16831686, 2000.

Ovarlez, J. and H. Ovarlez: Stratospheric water vapour content evolution during EASOE, Geophys. Res. Lett., 21, 1235-1238, 1994.

Pan, L. L., Randel, W. J., Nakajima, H., Massie, S. T., Kanzawa, H., Sasano, Y., Yokota, T., Sugita, T., Hayashida, S., and Oshchepkov, S.: Satellite observation of dehydration in the Arctic Polar stratosphere, Geophys. Res. Lett., 29, 1184, doi:10.1029/2001GL014147, 2002.

Peter, T., Müller, R., Crutzen, P., and Deshler, T.: The lifetime of leewaveinduced ice particles in the Arctic stratosphere; II, Stabilization due to NAT-coating, Geophys. Res. Lett., 21, 1331-1334, 1994.

Pitts, M. C., Thomason, L. W., Poole, L. R., and Winker, D. M.: Characterization of Polar Stratospheric Clouds with spaceborne lidar: CALIPSO and the 2006 Antarctic season, Atmos. Chem. Phys., 7, 5207-5228, doi:10.5194/acp-7-5207-2007, 2007.

Pitts, M. C., Poole, L. R., Dörnbrack, A., and Thomason, L. W.: The 2009-2010 Arctic polar stratospheric cloud season: a CALIPSO perspective, Atmos. Chem. Phys., 11, 2161-2177, doi:10.5194/acp-11-2161-2011, 2011.

Rosen, J. M. and Kjome, N. T.: Backscattersonde - A new instrument for atmospheric aerosol research, Appl. Opt., 30, 1552$1561,1991$.

Salawitch, R. J., Wofsy, S. C., Gottlieb, E. W., Lait, L. R., Newman, P. A., Schoeberl, M. R., Loewenstein, M., Podolske, J. R., Strahan, S. E., Proffitt, M. H., Webster, C. R., May, R. D., Fahey, D. W., Baumgardner, D., Dye, J., Wilson, J. C., Kelly, K. K., Elkins, J. W., Chan, K. R., and Anderson, J. G.: Chemical loss of ozone in the Arctic polar vortex in the winter of 1991-1992, Science, 261, 1146-1154, 1993.

Schiller, C., Bauer, R., Cairo, F., Deshler, T., Dornbrack, A., Elkins, J., Engel, A., Flentje, H., Larsen, N., Levin, I., Muller, M., Oltmans, S., Ovarlez, H., Ovarlez, J., Schreiner, J., Stroh, F., Voigt, C., and Vomel, H.: Dehydration in the Arctic stratosphere during the SOLVE/THESEO-2000 campaigns, J. Geophys. Res., 107, 8293, doi:10.1029/2001JD000463, 2002.

Schiller, C., Krämer, M., Afchine, A., Spelten, N., and Sitnikov, N.: The ice water content of Arctic, mid latitude and tropical cirrus, J. Geophys. Res., 113, D24208, doi:10.1029/2008JD010342, 2008.

Sitnikov, N. M., Yushkov, V. A., Afchine, A. A., Korshunov, L. I., Astakhov, V. I., Ulanovskii, A. E., Kramer, M., Mangold, A., Schiller, C., and Ravegnani, F.: The FLASH instrument for water vapour measurements on board the high-altitude airplane, Instrum. Exp. Tech., 50, 113-121, doi:10.1134/S0020441207010174, 2007.

Stone, E. M., Tabazadeh, A., Jensen, E., Pumphrey, H., Santee, M. L., and Mergenthaler, J. L.: Onset, extent, and duration of dehydration in the Southern Hemisphere polar vortex, J. Geophys. Res., 106, 22979-22989, 2001.

Vömel, H., Oltmans, S. J., Hofmann, D. J., Deshler, T., and Rosen, J. M.: The evolution of the dehydration in the Antarctic stratospheric vortex, J. Geophys. Res., 100, 13, 919-926, 1995.

Vömel, H., Rummukainen, M., Kivi, R., Karhu, J., Turunen, T., Kyrö, E., Rosen, J. M., Kjome, N. T., Oltmans, S. J.: Dehydration and sedimentation of ice particles in the Arctic stratospheric vortex, Geophys. Res. Lett., 24, 795-798, 1997.

Vömel, H., David, D. E., and Smith, K.: Accuracy of tropospheric and stratospheric water vapour measurements by the cryogenic frost point hygrometer: Instrumental details and observations, J. Geophys. Res., 112, D08305, doi:10.1029/2006JD007224, 2007a.

Vömel, H., Yushkov, V., Khaykin, S., Korshunov, L., Kyrö, E., and Kivi, R.: Intercomparisons of Stratospheric Water Vapour Sensors, FLASH-B and NOAA/CMDL Frost-Point Hygrometer, J. Atmos. Oceanic Technol., 24, 941-952, 2007b.

Waters, J. W., Froidevaux, L., Harwood, R. S., Jarnot, R. F., Pickett, H. M., Read, W. G., Siegel, P. H., Cofield, R. E., Filipiak, M. J., Flower, D. A., Holden, J. R., Lau, G. K. K., Livesey, N. J., Manney, G. L., Pumphrey, H. C., Santee, M. L., Wu, D. L., Cuddy, D. T., Lay, R. R., Loo, M. S., Perun, V. S., Schwartz, M. J., Stek, P. C., Thurstans, R. P., Boyles, M. A., Chandra, K. M., Chavez, M. C., Chen, G. S., Chudasama, B. V., Dodge, R., Fuller, R. A., Girard, M. A., Jiang, J. H., Jiang, Y. B., Knosp, B. W., LaBelle, R. C., Lam, J. C., Lee, K. A., Miller, D., Oswald, J. E., Patel, N. C., Pukala, D. M., Quintero, O., Scaff, D. M., Van Snyder, W, Tope, M. C., Wagner, P. A., and Walch, M. J.: The Earth Observing System Microwave Limb Sounder (EOS MLS) on the Aura satellite, IEEE T. Geosci. Remote Sens., 44, 1075-1092, 2006.

Wernli, H. and Davies, H. C.: A Lagrangian-based analysis of extratropical cyclones. I: The method and some applications, Q. J. Roy. Meteor. Soc., 123, 467-489, 1997.

Winker, D. M., Vaughan, M. A., Omar, A. H., Hu, Y., Powell, K. A., Liu, Z., Hunt, W. H., and Young, S. A.: Overview of the CALIPSO Mission and CALIOP Data Processing Algorithms, J. Atmos. Oceanic Technol., 26, 2310-2323, doi:10.1175/2009JTECHA1281.1, 2009.

Yushkov, V., Merkulov, S., and Astakhov, V.: Optical balloon hygrometer for upper stratosphere and stratosphere water vapour measurements, in Optical remote sensing of the atmosphere and clouds edited by: J. Wang, B. Wu, T.Ogawa, and Z.-H. Guans, Proc. SPIE, 3501, 439-445, 1998. 
Zöger, M., Afchine, A., Eicke, N., Gerhards, M.-T., Klein, E., McKenna, D. S., Mörschel, U., Schmidt, U., Tan, V., Tuitjer, F., Woyke, T., and Schiller, C.: Fast in situ stratospheric hygrometers: A new family of balloonborne and airborne Lyman $\alpha$ photofragment fluorescence hygrometers, J. Geophys. Res., 104, 1807-1816, 1999. 